\title{
FACTOR XII - A LIMITATION FOR DIVERS?
}

\author{
Piotr Radziwon ${ }^{1,2)}$, Romuald Olszański ${ }^{3)}$, Jolanta Korsak ${ }^{4)}$, Piotr Siermontowski ${ }^{3)}$, Zbigniew Dąbrowiecki $^{3)}$ \\ 1) Haematology Clinic, Medical University of Białystok, Poland \\ Regional Blood Donation and Haemotherapy Centre in Białystok, Poland \\ The Institute of Maritime and Hyperbaric Medicine of the Military Institute of Medicine in Gdynia, Poland \\ 4) Department of Transfusion Medicine, Military Institute of Medicine in Warsaw, Poland
}

\section{ABSTRACT}

The lack of evidence for the tissue-factor dependent activation of the coagulation system and the release of thrombin on one hand, and a decreased concentration of factor XII after short term air, saturated air and heliox exposures, as well as an increased concentration of the plasmin-antiplasmin complex (PAP) after short dives indicate that diving and decompression possibly affect fibrinolysis. The aim of our research was to verify the assumption that diving and decompression activate the system of fibrinolysis and the clarification of the pathomechanism of this activation.

The study involved 50 healthy volunteers who were subjected to short-term, air hyperbaric exposures at $400 \mathrm{kPa}$ and $700 \mathrm{kPa}$, which correspond to $30 \mathrm{~m}$ and $60 \mathrm{~m}$ dives. Decompression was applied in accordance with Naval tables of decompression. Before hyperbaric exposition and after decompression the following factors were determined: activity of factor XII, concentration and activity of t-PA, concentration and activity of PAI-1, concentration of alpha ${ }_{2-}$ antiplasmin, concentration of PAP, concentration of neutrophil elastase.

The following observations have been made: a statistically significant increase in the factor XII activity, increase in the PAP complex concentration and a simultaneous significant decline in the $\alpha_{2}-\mathrm{AP}$ activity. No measurable t-PA activity or significant changes in t-PA concentration have been observed. In addition, a statistically significant decline in both the activity and concentration of PAl-1 has been observed, which was more pronounced after the expositions that corresponded to $60 \mathrm{~m}$ dives. The concentrations of granulocyte elastase did not differ significantly before and after decompression. Conclusions: People qualified for diving should have the following risk factors examined: risk factors of increased fibrynolytic activity - haemostasis abnormalities that increase the risk of haemorrhage, possibility of parietal blood clots/thrombi.

Key words: diving, hyperbaric oxygenation, decompression, fibrinolysis, factor XII.

\section{ARTICLE INFO}

PolHypRes 2015 Vol. 52 Issue 3 pp. 7-16

ISSN: $1734-7009$ elSSN: $2084-0535$

DOI: $10.1515 / p h r-2015-0012$

Pages: 10, figures: 1 , tables: 3

page www of the periodical: www.phr.net.pl

Publisher

Polish Hyperbaric Medicine and Technology Society
Original article

Delivery date: $15.06 .2015 \mathrm{r}$

Date of approval for print: $12.07 .2015 \mathrm{r}$

Research carried out under the following projects: KBN 2PO5D 10526; N N404 468534. 


\section{INTRODUCTION}

Decompression sickness (DCS) and avascular necrosis (AVN) still remain significant problems of underwater medicine regardless of all the progress made in pursuit of improving safety in diving in the last century, continual improvement of diving equipment, application of breathing mixtures, correction of decompression tables and the use of visual techniques to monitor the gas bubbles appearing in blood vessels. More sensitive and specific safety evaluation parameters of decompression are yet to be found.

Observable changes in the number and activation of platelets and the occurrence of blood clots and platelet aggregation in the blood vessels of the spinal cord and femoral veins of divers who had died in the course of DCS, attracted attention to a possible role of homeostasis in the DCS pathomechanism and avascular necrosis $[1,2,3]$. The assumption of one of the theories is that the closure of nutrient vessels of bones with blood clots is the cause of AVN in divers [4,5].

The validity of the theory was corroborated by tests of animal models [6-9] and observations made in humans when diving, which confirmed $([10,11]$ the decline in the total number of platelets, as well as their activation and increase in the number of platelet aggregations and micro platelets after diving. The activation of blood platelets is considered to take place on the surface of gas bubbles forming during decompression [12-14]. This is corroborated by in vitro tests which prove the formation of platelet aggregations on the surface of gas bubbles in the course of their flow through plateletrich plasma [15-17].

Further evidence for assuming the thrombotic mechanism of DCS and AVN was provided by Goad et. al. in the 1970s, who described the shortening of prothrombin time and partial thromboplastin time after activation in people following 70 and $40 \mathrm{~m}$ dives [18], and Hart [19], who observed an increased concentration of fibrin/fibrinogen degradation products. Also Boussuges et al. interpreted the obtained test results as an activation of blood coagulation [20]. These observations were not confirmed by Eckenhoff and Hughes who examined divers exposed up to $50 \mathrm{~m}$, yet they established a statistically significant decline in fibrinogen concentration [21].

In other tests where divers were subjected to saturation dives with air, a decline in factor XII and X, as well as fibrinogen concentrations were observed [22]. Saturation hyperbaric expositions with the use of heliox produced the same effect to factor XII and fibrinogen $[11,22]$. Short term dives also contributed to the decline in factor XII and fibrinogen concentration. On the other hand, Goad et al. in their tests did not observe any changes in the concentration of coagulation factors: II, V, VII, X or fibrinogen [18]. Even though Gris et al. suggested a possibility of activating blood coagulation by a route that would be dependent on the tissue factor existed, based on the recorded increase in factor VII concentration after dives, their opinions do not seem to be corroborated [23].

Doubts as to the validity of the theory which postulates that diving and/or decompression cause the activation of blood coagulation, which may lead to the formation of blood clots, were raised by the research conducted by Olszański et al. where the influence of hyperbaric exposition and decompression on APTT, PT,
TT, tissue factor concentration (TF), TFPI, AT, III, the TAT complex, F1+2 fragment or the concentration of factor VII were not observed [5,22].

The lack of evidence for the tissue-factor dependent activation of the coagulation system and the release of thrombin on one hand, and the decreased concentration of factor XII after short term air, saturation, air and heliox exposures, as well as an increased concentration of the plasmin-antiplasmin complex (PAP) after short air and trimix dives, focused attention on the possibility of fibrinolysis activation [2].

An additional argument that points to the necessity of testing the influence of diving and decompression on the fibrinolytic system were the reports of haemorrhage cases in airways, within the inner and middle ear and the mastoid process, as well as the haemorrhagic stroke of the central nervous system, or haemorrhages in the subperiosteal area of the orbital cavity that occurred in the course of diving but not as a result of injuries or coincidence of other diseases [2429].

The aim of our research was to verify the assumption that diving activates the fibrinolytic system and the clarification of the pathomechanism of this activation.

\section{MATERIAL AND METHODS}

\section{Persons}

The study involved 50 healthy volunteers experienced in diving. These people were qualified for tests on the basis of an interview and a physical examination. After decompression, every diver underwent a Doppler examination of the subclavicular veins in order to detect the presence of gas bubbles in the circulatory system. For this purpose a Doppler Bubble Monitor (DBM9610 by Techno Scientific Inc. from Canada) ultrasonic detector was used. The intensity of the appearing gas bubbles was expressed as a 3-digit code in Kisman-Masurel classification.

Hyperbaric expositions were conducted in the DGKN - 120 habitat of the Department of Diving Equipment and Underwater Works Technology of the Polish Naval Academy in Gdynia. The use of the hyperbaric chamber allowed the creation of comparable exposition conditions for all the respondents by taking into account factors that affect the haemostatic system such as the breathing mixture used, physical effort and ambient temperature. All respondents breathed air and were not subjected to physical exertion.

Short term simulated air expositions which corresponded to 30 and $60 \mathrm{~m}$ dives were performed by 25 divers in each group.

The pressure used in the hyperbaric chamber was $400 \mathrm{kPa}$ (which corresponds to 30 m dives) - group I, and $700 \mathrm{kPa}$ which corresponds to $60 \mathrm{~m}$ dives - group II and remaining under this pressure (plateau) for $30 \mathrm{~min}$. (table 1).

Next, gradual decompression was used according to Naval tables. For safety reasons, after the exposition to the pressure of $700 \mathrm{kPa}$ the decompression profile that was used corresponded to that of diving at 63 metres, which in turn corresponds to the pressure of 735 $\mathrm{kPa}$, and after the exposition to the pressure of $400 \mathrm{kPa}$ the decompression profile used corresponded to diving at 33 metres, which was equal to the pressure of $440 \mathrm{kPa}$, 
(table 2). During the dives in the hyperbaric chamber, air was used for breathing. The exposition to $60 \mathrm{~m}$ was selected as it is maximum allowable diving depth with the use of air, whereas $30 \mathrm{~m}$ was chosen as it is half of the allowable depth.

Tab. 1.

Expositions run in the DGKN-120 habitat

\begin{tabular}{lllllll}
\hline $\begin{array}{l}\text { Pressure } \\
(\mathrm{kPa})\end{array}$ & Relevant depth (m) & $\begin{array}{l}\text { Breathing } \\
\text { mixture }\end{array}$ & $\begin{array}{l}\text { Number } \\
\text { of expositions }\end{array}$ & Plateau time & $\begin{array}{l}\text { Decompression } \\
\text { time }\end{array}$ & $\begin{array}{l}\text { Number } \\
\text { people }\end{array}$ \\
\hline 400 & 30 & Air & 5 & $30 \mathrm{~min}$ & $35 \mathrm{~min}$ & 25 \\
\hline 700 & 60 & Air & 5 & $30 \mathrm{~min}$ & $3 \mathrm{~h} 41 \mathrm{~min}$ & \\
\hline
\end{tabular}

Decompression profile implemented after diving at $30 \mathrm{~m}$ and $60 \mathrm{~m}$ according to Naval tables

Time of Elevation time to the Depth of the compression stage [m]

Diving depth staying at a Elevation time to the [m] given depth pression [min]

General

decompression

Time of staying at stages of time decompression [min]

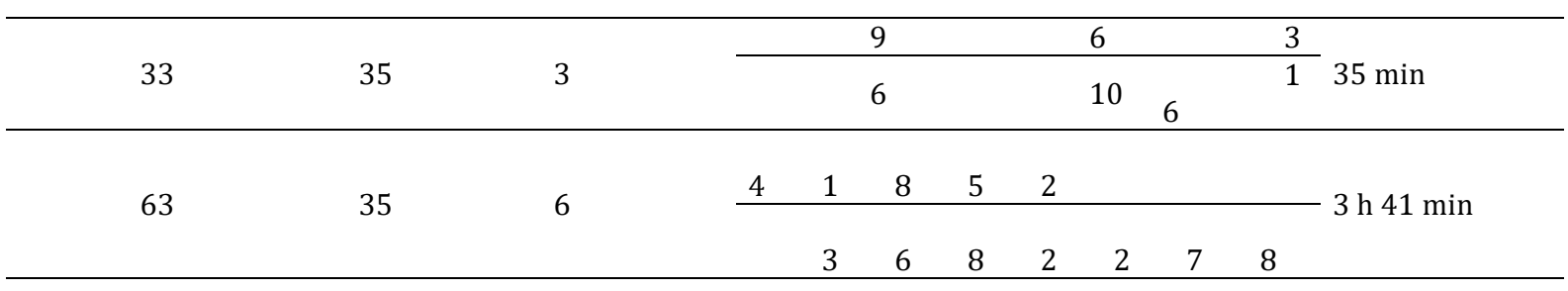

Table 2 shows data from Naval decompression tables regarding the profile of gradual decompression for a diver with the use of air, at $33 \mathrm{~m}$ and $63 \mathrm{~m}$ respectively when the duration at this depth is $30 \mathrm{~min}$. The table presents a minimum time of reaching the first decompression stop (for a $33 \mathrm{~m}$ dive it is 9 metres and for the exposition at 63 metres - $24 \mathrm{~m}$ ), the following decompression stops and duration of stay at each of them, as well as general decompression time.

\section{Laboratory tests}

Venous blood samples for tests were taken before hyperbaric exposition and after the decompression completed.

The activity of factor XII was measured with the use of the coagulation factor XII deficient plasma (human) (Dade Behring, Germany) and partial thromboplastin time after activation. The results were presented as a percentage of correct values.

Fibrinolytic system

Labelling: concentrations and activity of t-PA were performed with the use of the t-PA Combi Actibind ELISA Kit (Technoclone, Austria), PAI-1 concentrations were performed with the use of the PAI-1 Antigen ELISA (Technoclone, Austria), PAI-1 activity was performed with the PAI-1 Actibind ELISA (Technoclone, Austria), concentrations of alphaz-antiplasmin were performed with the use of the Unitest $\alpha_{2} \mathrm{AP}$ (Unicorn Diagnostics, Great Britain), concentrations of PAP were performed with the Enzygnost PAP micro kit (DadeBehring, Germany).
Elastase

The measurements of neutrophil elastase concentration were made in accordance with the method by Yoshimur et al. (30).

\section{RESULTS}

None of the exposed divers were diagnosed with a decompression sickness or had gas bubbles detected with the Doppler method. The level of haematocrit did not vary significantly in either of the studied groups before or after the expositions, which excludes the influence of blood composition changes on the concentration of the tested parameters in plasma.

As a result of short term hyperbaric expositions which corresponded to the 30 and 60 metre dives, a statistically significant increase of the factor XII activity was observed. 


\begin{tabular}{|c|c|c|c|c|c|c|c|}
\hline \multirow[t]{2}{*}{ Tested parameters } & \multicolumn{3}{|c|}{ Expositions of $400 \mathrm{kPa}$} & \multirow[t]{2}{*}{$\mathrm{p}$} & \multicolumn{3}{|c|}{ Expositions of $700 \mathrm{kPa}$} \\
\hline & Before & After & & & Before & After & \\
\hline Factor XII activity (\%) & 120 & 130 & .05 & $<0$ & 113 & 124 & 0.05 \\
\hline PAP (ng/ml) & $60.35 \pm 25.40$ & $69.18 \pm 28.63$ & .05 & $<0$ & $\begin{array}{l}57.19 \pm 18.0 \\
5\end{array}$ & $76.75 \pm 43.06$ & 0.05 \\
\hline Activity of $\alpha_{2}-\mathrm{AP}(\mathrm{U} / \mathrm{ml})$ & $1.06 \pm 0.23$ & $0.64 \pm 0.19$ & .05 & $<0$ & $1.06 \pm 0.25$ & $0.94 \pm 0.19$ & 0.05 \\
\hline Activity of t-PA (U/ml) & 0 & 0 & .05 & $>0$ & 0 & 0 & 0.05 \\
\hline Concentration of t-PA (ng/ml) & $9.46 \pm 5.59$ & $8.45 \pm 4.68$ & .05 & $>0$ & $9.12 \pm 5.01$ & $8.84 \pm 4.75$ & 0.05 \\
\hline PAI-1 activity $(\mathrm{U} / \mathrm{ml})$ & $8.57 \pm 4.86$ & $5.67 \pm 2.99$ & .001 & $<0$ & $10.36 \pm 8.03$ & $5.56 \pm 2.63$ & $\begin{array}{l}0.00 \\
1 \\
\end{array}$ \\
\hline PAI-1 concentration (ng/ml) & $3.92 \pm 2.05$ & $2.75 \pm 2.56$ & .01 & $<0$ & $5.14 \pm 3.28$ & $2.68 \pm 2.0$ & $\begin{array}{l}0.00 \\
1 \\
\end{array}$ \\
\hline Elastase concentration (ng/ml) & $30.1 \pm 13.5$ & $29.9 \pm 11.7$ & .05 & $>0$ & $28.7 \pm 13.7$ & $29.7 \pm 15.9$ & 0.05 \\
\hline
\end{tabular}

A statistically significant increase of the PAP complex concentration was observed, which was more pronounced after the exposition to the pressure of 700 $\mathrm{kPa}$, together with a statistically significant decline of $\alpha_{2-}$ $\mathrm{AP}$ at the same time.

In the measurements made both before and after expositions that corresponded to the 30 and $60 \mathrm{~m}$ dives no measurable activity of t-PA was observed, and the observable changes of t-PA concentration were not statistically significant.

After the hyperbaric expositions that correspond to the 30 and $60 \mathrm{~m}$ dives, a statistically significant decline of both the activity and concentration of PAI-1 was observed, which was more pronounced after the expositions corresponding to the $60 \mathrm{~m}$ dives.

The concentrations of granulocyte elastase did not differ significantly in either of the groups before and after decompression.

\section{DisCuSSION}

Test results unambiguously prove that diving causes the activation of platelets, activation of factor XII, plasmin generation and consumption of antiplasmin, as well as the decline in the activity and concentration of PAI-1. Factor XII belongs to the so-called contact factors whose activation is effected through the contact with a non-physiological surface such as kaolin or glass. In divers, such an alien surface may only be comprised of micro-bubbles of gas which are formed during decompression.

The activation of platelets may also be explained by the contact with gas bubbles. However, establishing the possible pathomechanism of declining PAI-1 was a true puzzle. While the air bubbles were the only change which might have affected the activation of factor XII, the responsibility for an observable change of PAI-1 may lie with several mechanisms. One of them is the consumption of PAI-1 related to the inhibition of the tissue plasminogen activator ( $t-P A)$.

The lack of t-PA concentration increase after hyperbaric expositions rather excludes this mechanism
[31]. Yet another cause of decline in PAI-1 concentration could be its degradation by elastase released from the activated granulocytes [32]. The increase in granulocyte number was observed by Olszański et al. [33]. However, the conducted tests of elastase concentration did not demonstrate the influence of hyperbaric expositions on its changes. In the light of the above facts a new interesting question emerged about the relationship of the increased activity of factor XII and the decline in the activity and concentration of PAI-1. The research conducted by Tanaka et al. helped to answer this question as they demonstrated the results of in vitro tests that indicate PAI-1 inactivation through the active factor XII [34].

We are convinced that in the course of diving, or decompression to be more precise, gas micro-bubbles are generated, which comprise an alien non-physiological surface to which platelets and contact factors may cling. The increase in factor XII activity causes the lysis of PAI-1. A lower PAI-1 concentration and activity cause the PAI-1 - t-PA imbalance in favour of t-PA, which leads to the increase in the amount of generated plasmin as a result. Plasmin is in turn neutralised by antiplasmin which is proved by an increased number of PAP complexes and a lower antiplasmin concentration (Fig. 1). 


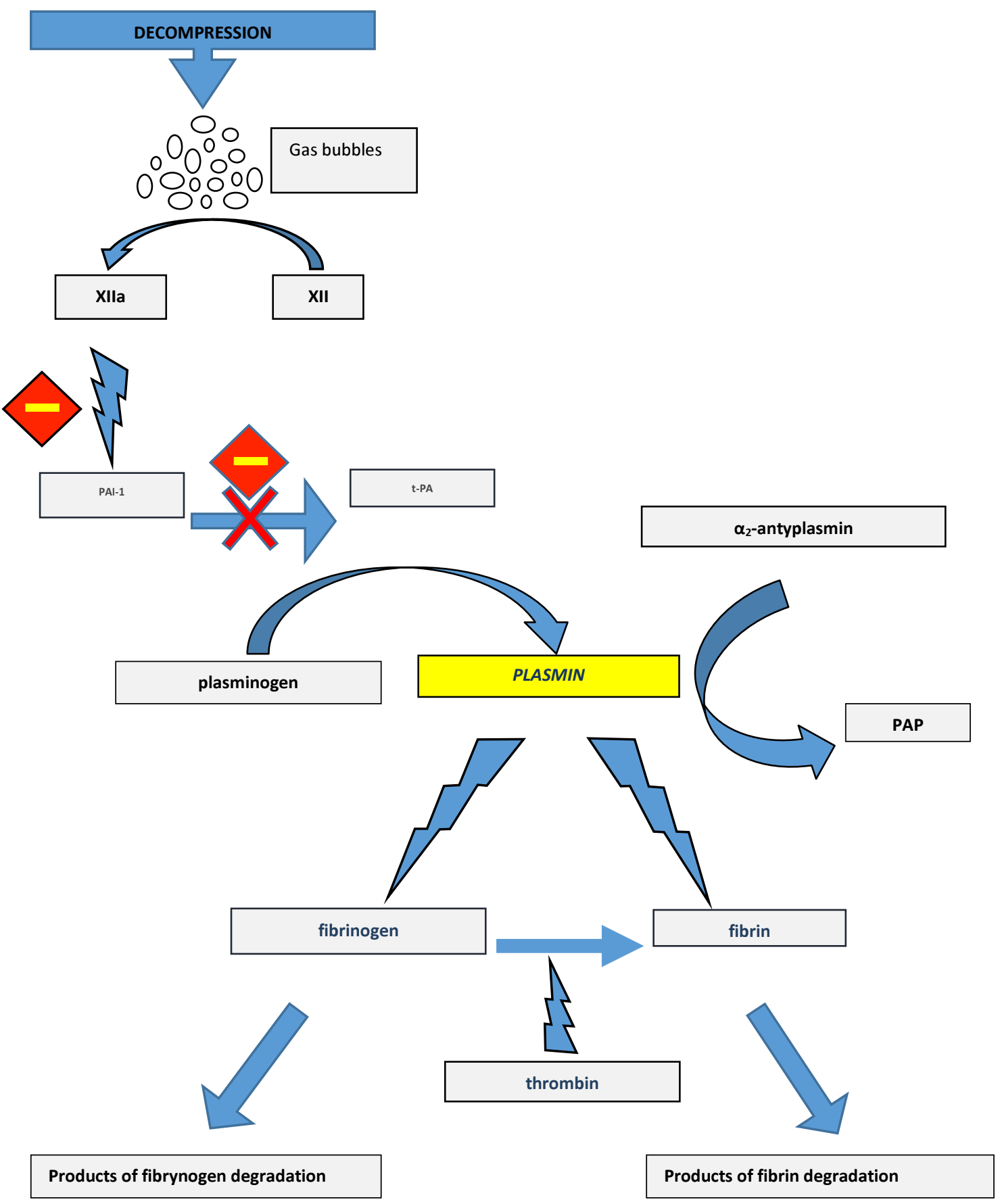

Fig. 1. Pathomechanism of the increased fibrinolytic activity in divers.

It is difficult to judge whether the increase in fibrinolytic activity may affect the incidence of decompression sickness in divers. However, it may explain the numerous reports of haemorrhage which occurred in people while diving, as well as cases of diagnosed strokes which may have been brought about by the lysis of the fragments of existing blood clots (e.g. within varicose veins or in the atrium in people with a diagnosed atrial fibrillation) and not by the activation of blood coagulation.

Is the activation of factor XII and fibrinolysis as its consequence important from the point of view of diving safety? We are convinced that the answer is affirmative. One group of people in whom the activation of fibrinolysis may carry a true risk are the patients with varicose veins, atrial fibrillation, or other disease which is conducive to the formation of parietal blood clots.

The plasmin, which is generated while diving, may release a blood clot or its fragment which may cause an embolus that may threaten the health or life of the diver. Another risk related to the fibrinolytic activity may be observed in patients who have experienced injuries or undergone surgical procedures with only just healed wounds, as the clots may be consumed bringing about the 
haemorrhage. The third risk group is constituted by those patients who have bleeding tendencies, including patients with haemophilia and other haemorrhagic diatheses. The increase in the generated plasmin may bring imbalance to haemostasis in such patients and bring about haemorrhages.

An additional and convincing argument to attribute great significance to factor XII has been provided by nature itself. Mammals, for whom water and diving are their element, such as dolphins and whales do not suffer from decompression sickness, even though they do not use decompression tables. Maybe the key to their safe diving is the lack of factor XII or its activity in their blood coagulation system [35-37].

\section{ConClusion}

People qualified for diving should have the following risk factors examined: risk factors of increased fibrynolytic activity - haemostasis abnormalities that increase the risk of haemorrhage, possibility of parietal blood clots/thrombi.

\section{BIBLIOGRAPHY}

Kawashima M, Hayashi K, Torsiu T, Kitano M. Hystopathology of the early stage of osteonecrosis in vivers. Undersea Biomed Res 1977;4:409-417. Kawashima M, Torisu T, Hayashi K, Kitano M. Pathological review of osteonecrosis in divers. Clin Orthop Relat Res 1978;130:107-117.

3. Kitano M. Three autopsy cases of acute decompression sickness-Consideration of pathogenesis about spinal cord damage in decompression sickness J West Jap Orthop Traum 1977;26:402-408

4. Kawashima M, Tamura H, Noro $\mathrm{Y}$, Takao K, Kitano M, Lehner ChE, Taya $\mathrm{Y}$, Mano $\mathrm{Y}$, Tsunosue $\mathrm{T}$. Pathogenesis and prevention of dysbaric osteonecrosis. Decompression Sickness in Divers. Kagashima Univ Res Center S Pac Occasional Papers 1995;25:37-46.

5. Slichter SJ, Stegall P, Smith K, Huang TW, Harker LA. Dysbaric osteonecrosis a consequence of intravascular bubble formation, endothelial damage, and platelet thrombosis. J Lab Clin Med 1981;98:69-90.

6. Kuroiwa K. The functional and biochemical changes of platelets in experimental decompression sickness of rabbits. Bull Tokyo Med Dent Univ 1984;31:73-84.

7. Paradowski A, Wronkowska G. Decompression profiles in experiments on animals versus changes of the selected haemostasis indicators. Polski przegląd medycyny lotniczej 1999;2:125-132.

8. Philp RB Involvement of platelets and microthrombi in experimental decompression sickness: Similarities with disseminated intravascular coagulation. Aerospace Med 1971;42:494-502.

9. Tanoue K, Mano Y, Kuroiwa K, Suzuki H, Shibayama M, Yamazaki H. Consumption of platelets in decompression sickness of rabbits. J Appl Physiol $1987 ; 2: 1772-1779$

10. Baj Z, Olszański R, Majewska E, Konarski M. The effect of air and nitrox diving on platelet activation tested by flow cytometry. Aviat Space Environ Med 2000;71:925-928.

11. Olszański R. Evaluation of heliox saturated diving on the basis of selected haemostasis parameters. Bull Inst. Marit Trop Med 1998;49:117-121

12. Hyldegaard O, Madsen J. Effect of air, heliox and oxygen breathing on air bubbles in aqueous tissues in the rat. Undersea Hyper Med 1994;21:413-424

13. Softeland E, Framstad T, Nordvik A, Strand I, Thorsen T, Holmsen H. Nitrogen microbubbles induce a disappearance of single platelets aggregation with porcine platelets: a comparative study of anticoagulants and blood collection methods. Thromb Res 1994:1:61-67.

14. Warren BA. The ultrastructural morphology of air embolism : Platelet adhesion to the interface and endothelial damage. Br J Exp Path 1973;54:163-172.

15. Pickles DM, Ogston D, MacDonald AG. Effects of gas bubbling and other forms of convection on platelets in vitro. J Appl Physiol 1989;67:250-255.

16. Thorsen T, Brubakk A, Ovstedal T, Farstad M, Holmsen H. A method for production of $\mathrm{N}_{2}$ microbubbles in platelet-rich plasma in an aggregometer-like apparatus and effect on the platelet density in vitro. Undersae Biomed Res 1986;13:271-288.

17. Thorsen T, Lie RT, Holmsen H. Induction of platelet aggregation in vitro by microbubbles of nitrogen. Undersea Biomed Res 1898:16:453-464.

18. Goad RF, Neuman TS, Linaweaver PGJr. Hematologic changes in man during decompression: relations to overt decompression sickness and bubble scores. Aviat Space Environ Med 1976;47:863-867.

19. Hart GB. Screening test for decompression sickness. Aviat Space Environ Med 1976;47:993-994

20. Boussuges A, Succo E, Juhan-Vague I, Sainty JM. Activation of coagulation in decompression illness. Aviat Space Environ Med 1998:69:129-132.

21. Eckenhoff RG, Hughes JS. Hematologic and hemostatic changes with repetitive air diving. Aviat. Space Environ Med 1984;55:592-597.

22. Olszański R, Radziwon P, Baj Z, Kaczmarek P, Giedrojć J, Galar M, Kłoczko J. Changes in the extrinsic and intrinsic coagulation pathways in humans after decompression following saturation diving. Blood, 2001;12:1-6

23. Gris JC, Arquizan T, Brunel C, Gillet JL, Grand D. Acute haemostasis activation after a scuba diving: generation if circulating activated factor VII and cellderived microparticles. Bulletin de Medicine Subaquatique et Hyperbare 1997:7:21-23.

24. Balk M, Goldman JM. Alveolar hemorrhage as a manifestation of pulmonary barotrauma after scuba diving. Ann Emerg Med 1990;19:930-934

25. Boussuges A, Succo E, Bergmann E, Sainty JM. Intra-alveolar hemorrhage. An uncommon accident in breath holding diver. Presse Med 1995;2:11691170.

26. Chen JC, Kucharczyk W. Nontraumatic orbital subperiosteal hematoma in scuba diver: CT and MR findings. J Comput Assist Tomogr 1988:12:504-506.

27. Green SM, Rothrock SG, Green EA. Tympanometrice-valuation of middle ear barotrauma during recreational scuba diving. Int J Sports Med 1993;14:411415.

28. Josefsen R, Wester K. Cerebellar hemorrhage - rare, but serious complication in decompression disease. Tidsskr Nor Laegeforen 1999;119:3901-3902

29. Sheridan MF, Hetherington HH, Hull JJ. Inner ear barotrauma from scuba diving. Ear Nose Throat J 1999:78:186-187.

30. Yoshimura K, Nakagawa S, Koyama S, Kobayashi T, Homma T. Roles of neutrophil elastase and superoxide anion in leukotriene B4-induced lung injury in rabbit. J Appl Physiol 1994;76:91-96.

31. Radziwon P, Olszański R, Tomaszewski R, Lipska A, Dąbrowicki Z, Korzeniewski K, Siermontowski P, Boczkowska-Radziwon B. Decreased levels of PAI1 and alpha ${ }_{2}$-antiplasmin contribute to enhanced fibrinolytic activity in divers. Thromb Res 2007;121:235-240.

32. Wu K, Urano T, Ihara H, Takada Y, Fujie M, Shikimori M, Hashimoto $\mathrm{K}$, Takada A. The cleavage and inactivation of plasminogen activator inhibitor type 1 by neutrophil elastase: the evaluation of its physiologic relevance in fibrinolysis. Blood 1995;86:1056-1061.

33. Olszański R, Konarski M, Kierznikowicz B. Changes of selected morphotic parameters and blood plasma proteins in blood of divers after a single shortterm operational exposure. Intern Marit Health 2002;53:111-121.

34. Tanaka A, Suzuki Y, Sugihara K, Kanayama N, Urano T. Inactivation of plasminogen activator inhibitor type 1 by activated factor XII plays a role in the enhancement of fibrinolysis by contact factors in vivo. Life Sci 2009;85:220-225.

35. Lohman S, Folkow LP, Osterud B, Sager G. Changes in fibrinolytic activity in diving grey seals. Comp Biochem Physiol A Mol Integr Physiol 1998;120:693-698

36. Robinson AJ, Kropatkin M, Aggeler PM. Hageman factor (factor XII) deficiency in marine mammals. Science 1969;166:1420-1422.

37. Semba U, Shibuya Y, Okabe H, Yamamoto T. Whale Hageman Factor (Factor XII): Prevented Production Due to Pseudogene Conversion. Thromb Res 1998;90:31-37.

prof. dr hab. n. med. Piotr Radziwon

Regional Blood Donation and Haemotherapy Centre in Białystok,

ul. Marii Skłodowskiej-Curie 23, 15-950 Białystok

tel: +48857447002

fax: +48 857447133

e-mail: piotr.radziwon@wp.pl 